Nodul at $i$ on of Emissi on I nt ensi ti es of Bi nary

Fi I ms Composed of $\mathrm{Fl}$ uor escent Amor phous

Nol ecul ar Naterial s and $p$-Tol uenesul foni c Aci d i $\mathrm{n}$ Response to Exhal ed $\mathrm{Br}$ eat $\mathrm{h}$

\begin{tabular}{|l|l|}
\hline 著者 & NAKANO H deyuki \\
\hline $\begin{array}{l}\mathrm{j} \text { our nal or } \\
\text { publ i cat } \mathrm{i} \text { on } \mathrm{t} \mathrm{i} \mathrm{tl} \text { e }\end{array}$ & Chemi st ry Sel ect \\
\hline vol une & 1 \\
\hline number & 8 \\
\hline page $\mathrm{r}$ ange & $1737-1740$ \\
\hline year & $2016-06-01$ \\
\hline URL & ht t p: //hdl . handl e. net $/ 10258 / 00009223$ \\
\hline
\end{tabular}




\title{
Modulation of Emission Intensities of Binary Films Composed of Fluorescent Amorphous Molecular Materials and p-Toluenesulfonic Acid in Response to Exhaled Breath
}

\author{
Hideyuki Nakano, ${ }^{*[a]}$ Tomohiro Nishimura, ${ }^{[a]}$ Eisuke Nagata, ${ }^{[a]}$ and Ryoji Ichikawa ${ }^{[a]}$
}

\begin{abstract}
We have found that fluorescence emission of binary films composed of fluorescent amorphous molecular materials, 4-[bis(4methylphenylaryl)amino]benzaldehyde (BMABA) and 4-[bis(4methylphenylaryl)amino]acetophenone (BMAAP), with $p$-toluenesulfonic acid (TsOH) was quenched at ambient dry atmosphere but enhanced when we breathed onto their films. When pausing the breath, the emission was again quenched. Moisture in the exhaled breath was suggested to play a role for such phenomena. It was suggested that some BMABA and BMAAP molecules were protonated in their films as prepared at ambient dry atmosphere and that protonation and deprotonation took place corresponding to change in surrounding humidity, resulting in modulation of emission intensity.
\end{abstract}

Stimuli-responsible emitting materials are the candidates for practical applications such as visible sensors and fluorescence switches triggered by external stimuli. Creation of such materials and investigation of their properties responsible to external stimuli to clarify the mechanism are attractive subjects. It is known that emitting organic molecules possessing intramolecular chargetransfer features often exhibit solvatochromic luminescence, their emission color depending upon the solvent polarity. ${ }^{[1]}$ Recently, emission color changes of molecules exhibiting excited-state intramolecular proton transfer induced by addition of proton and other ions into solutions have been reported. ${ }^{[2]}$ Several photochromic diarylethenes conjugated with emitting chromophore have been created to provide photo-switchable emitting materials. ${ }^{[3]}$ With regard to organic solid emitting materials, mechanochroimic fluorescence was recently attracting attentions. ${ }^{[4]}$ Aggregation induced emission (AIE) is also the recent subject of interest. ${ }^{[5]}$

In due course of our studies on creation of photo-functional low molecular-mass materials that readily form amorphous glasses above room temperature, namely amorphous molecular materials ${ }^{[6]}$ we have found that fluorescent amorphous molecular materials, 4-[bis(4-methylphenyl)amino]benzaldehyde (BMABA) and 4-[bis(4-methylphenyl)amino]acetophenone (BMAAP), exhibited not only solvatofluorochromism but also mechanofluorochromism. ${ }^{[6 b]}$ In addition, BMABA exhibited AIE by adding a droplet of the ethanol solution into water, and the

[a] Prof. H. Nakano, Mr. T. Nishimura, Mr. E. Nagata, Mr. R. Ichikawa Department of Applied Chemistry

Muroran Institute of Technology

27-1, Mizumoto-cho, Muroran, Hokkaido 050-8585, Japan

E-mail: nakano@mmm.muroran-it.ac.jp

Supporting information for this article is given via a link at the end of the document. emission color change of the aggregate could be induced by vigorous stirring on heating. ${ }^{[6 c]}$ Thus, these materials are promising candidates for stimuli-responsible emitters. Here we report the modulation of emission intensity of novel binary films of BMABA and BMAAP with p-toluenesulfonic acid (TsOH) in response to exhaled breath. Chemical structures of BMABA and BMAAP together with $\mathrm{TsOH}$ were shown in Scheme 1.
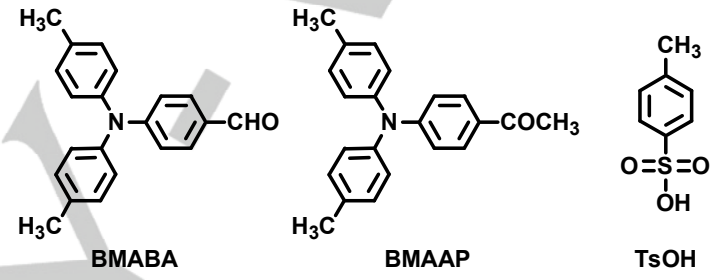

Scheme 1. Chemical structures of materials used in the present study.

Binary films of BMABA-TsOH and BMAAP-TsOH were prepared onto glass substrates by spin-coating method from THF solutions of the mixture of corresponding amorphous molecular materials and $\mathrm{TsOH} \cdot \mathrm{H}_{2} \mathrm{O}$ with a molar ratio of ca. 1:1. Although both singlecomponent BMABA and BMAAP films without $\mathrm{TsOH}$ exhibited fluorescence upon irradiation with UV light (365 nm), fluorescences of binary films of BMABA-TsOH and BMAAP$\mathrm{TsOH}$ were scarcely observed at ambient atmosphere $\left(\right.$ ca. $20^{\circ} \mathrm{C}$, ca. $20 \% \mathrm{RH}$ ). Interestingly, when we breathed onto these films upon irradiation with the UV light, bright fluorescence emissions were observed as shown in Figure 1. When pausing the breath, the emissions were again quenched gradually. Such reversible fluorescence changes of these films were also shown in Supporting Videos 1 and 2.

\section{A \\ B}
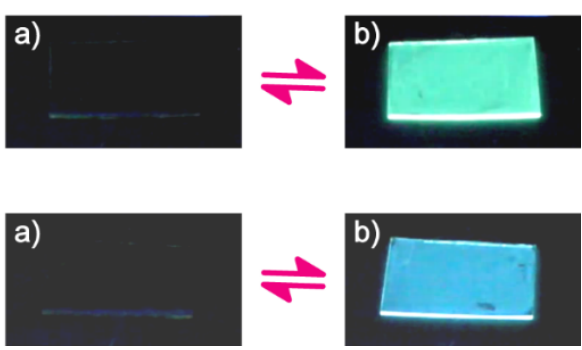

Figure 1. Photographs of (A) BMABA-TsOH and (B) BMAAP-TsOH films upon irradiation with UV light (365 nm). (a) At ambient dry atmosphere. (b) When breathing onto their films. 
When their films were in the stream of dry and hot air by means of a hair dryer, no such enhancement of fluorescence emission could be observed. The fluorescence could neither be enhanced when the films were exposed to hexane vapor. On the other hand, the bright emissions of the films were observed when they were exposed to water vapor, suggesting that moisture played a role for the present fluorescence enhancement by breathing onto the films. In fact, the fluorescence spectra of BMABA-TsOH film (Figure 2) showed that the emission intensity at ca. $70 \% \mathrm{RH}$ was considerably larger than that at ca. $30 \% \mathrm{RH}$.

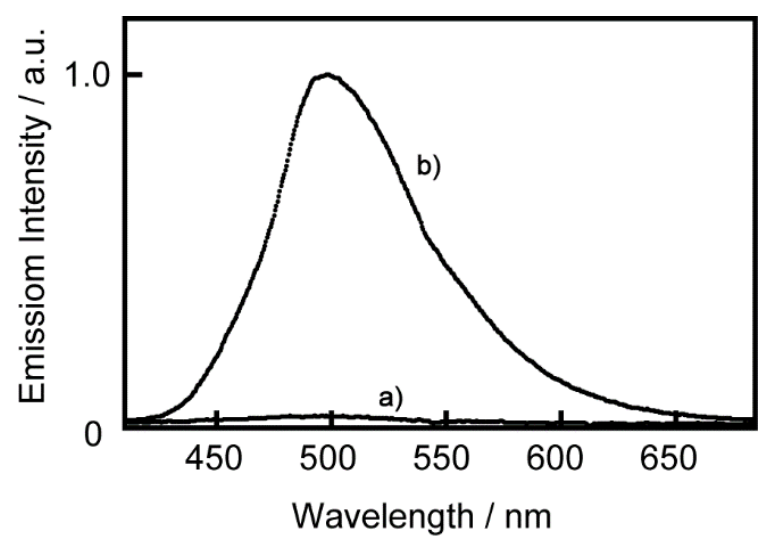

Figure 2. Fluorescence spectral changes of BMABA-TsOH by changing the humidity. a) ca. $30 \% \mathrm{RH}$, b) ca. $70 \% \mathrm{RH}$. $\lambda_{\text {ex: }} 365 \mathrm{~nm}$.

Not only fluorescence but also electronic absorption spectra of the films were found to change when breathing onto their films. As shown in Figure 3, the electronic absorption spectrum for BMABA-TsOH film at ambient dry atmosphere was somewhat red-shifted and broader relative to that for the film when breathing onto the film. As a result, the film was pale yellow as prepared but the color disappeared by breathing onto the film as shown in inset in Figure 3. The spectrum when breathing onto the film seemed to be similar to that for the single-component BMABA film.

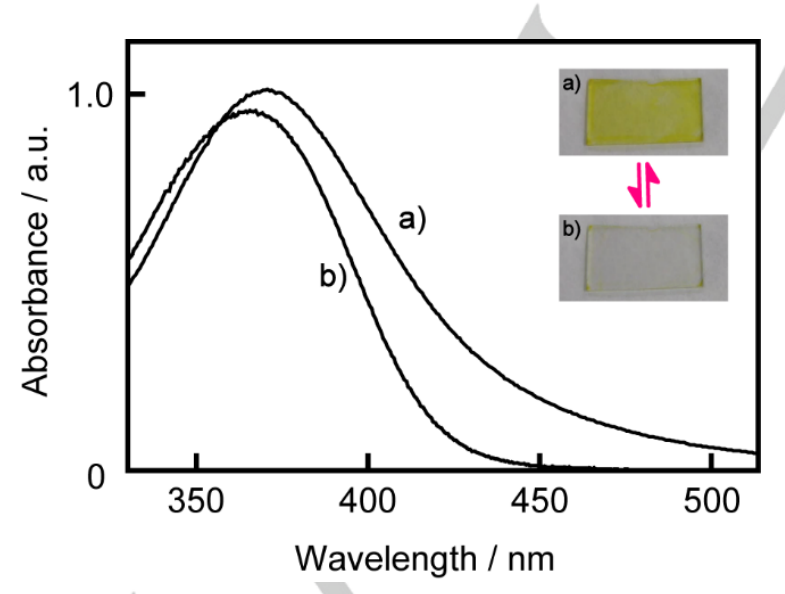

Figure 3. Electronic absorption spectra of BMABA-TsOH film at (a) ca. $20 \% \mathrm{RH}$ and (b) ca. $80 \%$ RH. Inset photographs: BMABA-TsOH film (a) at ambient dry atmosphere and (b) when breathing onto the film.
Due to relatively strong acidity of $\mathrm{TsOH}, \mathrm{BMABA}$ molecules were suggested to be protonated to produce $B M A B A-H^{+}$when the BMABA-TsOH film was prepared. Since resonance structures of BMABA- $\mathrm{H}^{+}$can be drawn as shown in Scheme 2, considerable red-shift of the electronic absorption spectrum by protonation may take place caused by extension of the conjugation as well as change in electronic structure by protonation. The red-shift of absorption band by protonation was also suggested by ab initio calculation based on density-function theory at $B 3 L Y P / 6-31+G(d, p)$ level, ${ }^{[7]}$ the electronic absorption maxima for BMABA and BMABA- $\mathrm{H}^{+}$being 367 and $476 \mathrm{~nm}$, respectively.

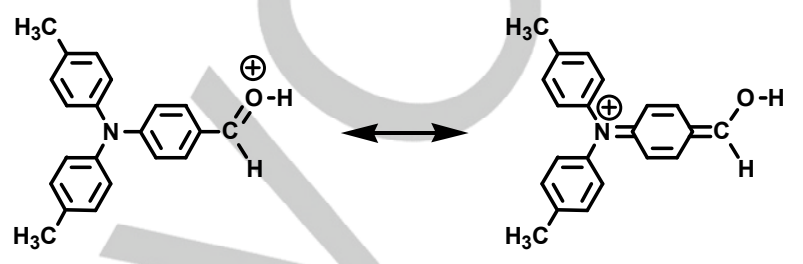

Scheme 2. Resonance structures of BMABA- $\mathrm{H}^{+}$.

We have previously reported that binary films of amorphous molecular materials based on 4-(diarylamino)azobenzenes with $\mathrm{TsOH}$ exhibited reversible color changes by breathing onto their films and concluded that protonation and deprotonation for the 4(diarylamino)azobenzenes took place in the binary films corresponding to change in surrounding humidity. ${ }^{\left[{ }^{[]}\right.}$Based on the similar consideration, present phenomena of reversible emission modulation of BMABA-TsOH film shown in Fig. 1 could be understood as follows. When the film was prepared at ambient dry atmosphere, some BMABA molecules were protonated by $\mathrm{TsOH}$ to produce BMABA- $\mathrm{H}^{+}$, resulting in slight red-shift with broadening of the electronic absorption spectrum and quenching the fluorescence of BMABA (Eq. 1 in Scheme 3). When we breathed onto the film, moisture in the exhaled breath was absorbed into the film and deprotonation by $\mathrm{H}_{2} \mathrm{O}$ took place (Eq. 2 in Scheme 3), resulting in decoloration of the film and emission enhancement due to disappearance of BMABA- $\mathrm{H}^{+}$. When pausing the breath, $\mathrm{H}_{2} \mathrm{O}$ evaporated immediately from the film, resulting in the recovery of BMABA- $\mathrm{H}^{+}$according to the backward reaction of Eq. 2 in Scheme 3. Likewise, BMAAP-TsOH film exhibited modulation of emission intensity in response to exhaled breath.

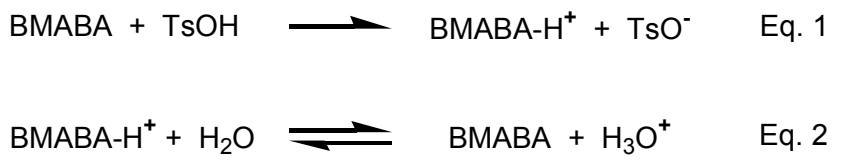

Scheme 3. Plausible reactions taking place in the BMABA-TsOH film

Unfortunately, the present binary films were found to have less repetition durability. As shown in Figure 4, emission intensity of BMABA-TsOH film gradually decreased during the on-off cycles. Since molecules possessing arylcarbonyl moieties often undergo 
photochemical reactions ${ }^{[9]}$ degradation of BMABA and BMAAP molecules might take place photochemically in their binary films upon irradiation with UV light. However, the present study provided an interesting and important concept for creation of exhaled moisture-sensitive functional films by using $\mathrm{TsOH}$. Further studies are in progress.

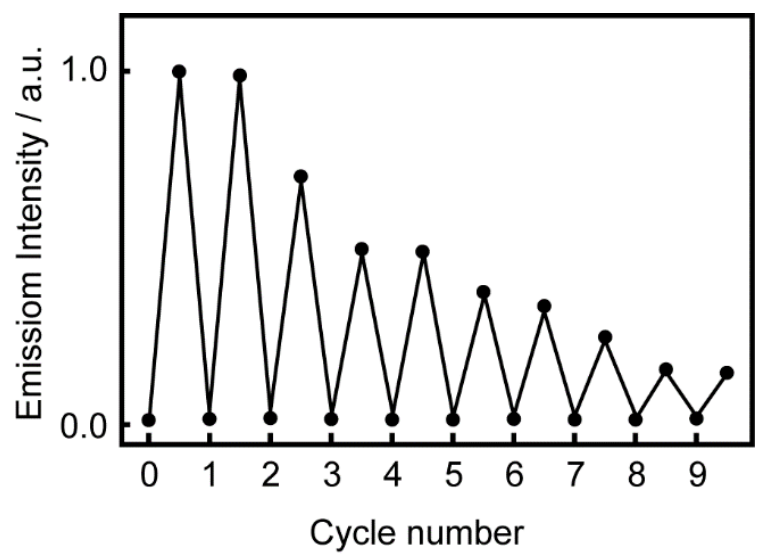

Figure 4. Change in emission intensity of a BMABA-TsOH film monitored at $500 \mathrm{~nm}$ upon on-off cycles of the breath.

In summary, we have created novel binary films that exhibit modulation of emission intensities in response to exhaled breath using emitting amorphous molecular materials, BMABA and BMAAP, with $\mathrm{TsOH}$. It was suggested that protonation and deprotonation of the emitter molecules took place according to change in humidity, resulting in modulation of emission intensity. Hybridization of $\mathrm{TsOH}$ and functional amorphous molecular materials with appropriate proton accepting ability is expected to provide novel functional films in response to exhaled breath.

\section{Experimental Section}

Materials: BMABA and $\mathrm{TsOH} \cdot \mathrm{H}_{2} \mathrm{O}$ were purchased commercially. BMAAP was prepared by the method reported in our previous paper. [6b]

Fluoresccence Spectroscopy: Fluorescence spectra were measured in a handmade Styrofoam box by means of BLUE-Wave miniature spectrometers (StellarNet., Inc.) with a light source for excitation, LED365SPT/L (OptoCode Corp.). For measuring the spectrum at high humidity (ca. $70 \% \mathrm{RH}$ ), the humidity around the sample films was increased by placing a wet paper in the box.

Electronic Absorption Spectroscopy: Electronic absorption spectra were measured by means of U-3500 spectrophotometer (Hitachi Ltd.) at room temperature. For measuring the spectrum at high humidity (ca. $80 \% \mathrm{RH}$ ), the humidity around the sample films was increased by placing a beaker with hot water in the sample room of the apparatus.

Keywords: Fluorescent amorphous molecular material $\bullet p$ -

Toluenesulfonic acid $•$ Binary film $•$ Exhaled breath $\bullet$ Moisture

[1] Z. R. Grabowski, K. Rotkiewicz, Chem. Rev. 2003, 103, 3899-4031; Samuel. W. Thomas III, G. D. Joly, T. M. Swager, Chem. Rev. 2007, 107, 1339-1386.

[2] K. Sakai, T. Ishikawa, T. Akutagawa, J. Mater. Chem. C 2013, 1, 78667871; Y. Nakane, T. Takeda, N. Hoshino, K. Sakai, T. Akutagawa, J. Phys. Chem. A 2015, 119, 6223-6231.

[3] G. M. Tsivgoulis, J.-M. Lehn, Angew. Chem. Int. Ed. 1995, 34, 11191122; T. B. Norsten, N. R. Branda, Adv. Mater. 2001, 13, 347-349; K. Yagi, C. F. Soong, M. Irie, J. Org. Chem. 2001, 66, 5419-5423; M. Irie, T. Fukaminato, T. Sasaki, N. Tamai, T. Kawai, Nature 2002, 420, 759760; T. Fukaminato, T. Doi, N. Tamaoki, K. Okuno, Y. Ishibashi, H. Miyasaka, M. Irie, J. Am. Chem. Soc. 2011, 133, 4984-4990.

[4] Y. Sagara, T. Kato, Nature Chem. 2009, 1, 605-610; Y. Ooyama, Y. Kagawa, H. Fukuoka, G. Ito, Y. Harima, Eur. J. Org. Chem. 2009, 53215326; G. Zhang, J. Lu, M. Sabat, C. L. Fraser, J. Am. Chem. Soc. 2010, 132, 2160-2162; Z. Chi, X. Zhang, B. Xu, X. Zhou, C. Ma, Y. Zhang, S. Liu, J. Xu, Chem. Soc. Rev. 2012, 41, 3878-3896; Y. Sagara, T. Komatsu, T. Ueno, K. Hanaoka, T. Kato, T. Nagano, J. Am. Chem. Soc. 2014, 136, 4273-4280; M. Zheng, D. T. Zhang, M. X. Sun, Y. P. Li, T. L. Liu, S. F. Xue, W. J. Yang, J. Mater. Chem. C 2014, 2, 1913-1920.

[5] Y. Hong, J. W. Y. Lam, B. Z. Tang, Chem. Soc. Rev., 2011, 40, 53615388; X. Zhang, Z. Chi, H. Li, B. Xu, X. Li, S. Liu, Y. Zhang, J. Xu, J. Mater. Chem., 2011, 21, 1788-1796; J. W. Chung, S.-J. Yoon, B.-K. An, S. Y. Park, J. Phys. Chem. C, 2013, 117, 11285-11291; J. Liang, Z. Chen, J. Yin, G.-A. Yu, S. H. Liu, Chem. Commun., 2013, 49, 3567-3569.

[6] a) Y. Shirota, J. Mater. Chem. 2000, 10, 1-25 and references cited therein; H. Inada, K. Ohnishi, S. Nomura, A. Higuchi, H. Nakano, Y. Shirota, J. Mater. Chem. 1994, 4, 171-177; H. Utsumi, D. Nagahama, H. Nakano, Y. Shirota, J. Mater. Chem. 2002, 12, 2612-2619; T. Tanino, S. Yoshikawa, T. Ujike, D. Nagahama, K. Moriwaki, T. Takahashi, Y. Kotani, H. Nakano, Y. Shirota, J. Mater. Chem. 2007, 17, 4953-4963; b) K. Mizuguchi, H. Kageyama, H. Nakano, Mater. Lett. 2011, 65, 2658-2661; K. Okoshi, H. Nakano, J. Photopolym. Sci. Tech. 2014, 27, 535-538; c) M. Kurita, M. Momma, K. Mizuguchi, H. Nakano, ChemPhysChem 2013, 14, 3898-3901.

[7] Gaussian 09, Revision D.01, Wallingford CT: Gaussian, Inc., 2013.

[8] R. Ichikawa, E. Nagata, H. Nakano, RSC Adv. 2015, 5, 2934-2937.

[9] A. G. Griesbeck, N. Hoffmann, K.-D. Warzecha, Acc. Chem. Res. 2007 40, 128-140; N. Hoffmann, Chem. Rev. 2008, 108, 1502-1103. 
Entry for the Table of Contents (Please choose one layout)

Layout 1:

\section{COMMUNICATION}

Text for Table of Contents

Layout 2:

\section{COMMUNICATION}
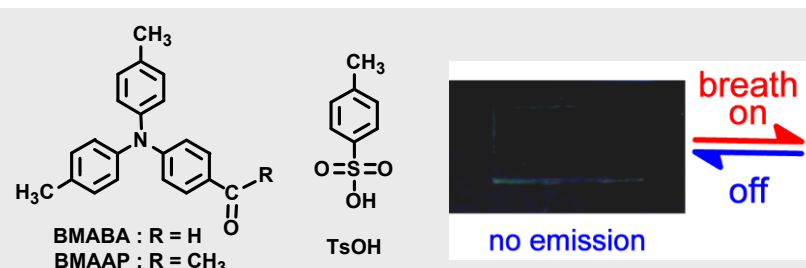

no emission

((Insert TOC Graphic here))

Author(s), Corresponding Author(s)*

Page No. - Page No.

Title

Novel binary films composed of emitting amorphous molecular materials (BMABA and BMAAP) with $p$-toluenesulfonic acid $(\mathrm{TsOH})$ were found to exhibit modulation of emission intensities in response to exhaled breath.

H. Nakano, ${ }^{*}$ T. Nishimura, E.Nagata, R. Ichikawa

Page No. - Page No.

Modulation of Emission Intensities of Binary Films Composed of Fluorescent Amorphous Molecular Materials and $p$-Toluenesulfonic Acid in Response to Exhaled Breath 